\title{
Case \\ Report \\ Imaging appearance of subependymoma: A rare tumor of the cord
}

\author{
Yadav RK, Agarwal S, Saini J, Sharma NK1 \\ Departments of Radiology and 'Neurosurgery, Pt. BDS PGIMS, Rohtak, Haryana, India
}

Correspondence to: Dr. Yadav RK, E-mail: rohtasyadav@yahoo.com

\begin{abstract}
Subependymoma of the cord are rare tumors with very few cases described in the literature. They represent a diagnostic dilemma as far as imaging and histopathology is concerned. They are biologically benign with low proliferative index, hence postoperative prognosis is very good. We present a case of a 42-year-old male patient with an intramedullary Subependymoma located within the central canal of thoracic region cord. On imaging with T1-weighted and T2-weighted sequences it mimicked syringohydromyelia, however, on heavily T2-weighted images the tumor located within the central canal could be delineated. The tumor was excised with complete recovery.
\end{abstract}

Key words: Cord, magnetic resonance imaging, subependymoma

\section{Introduction}

Subependymomas are slow growing tumors usually found in the ventricular system. ${ }^{[1]}$ They possibly account for less than $2 \%$ of all spinal cord tumors. ${ }^{[2]} \mathrm{O} n$ imaging studies they cannot be differentiated from ependymomas ${ }^{[3,4]}$ and can present a diagnostic dilemma. We present a 42-year-old male patient in whom the imaging findings on T1-weighted and T2-weighted Magnetic Resonance (MR) studies mimicked Syringohydromyelia, however on imaging with heavily T2-weighted sequence the tumor located within the central canal could be delineated. Contrast enhanced images did not show any enhancement.

\section{Case Report}

A 42-year-old male patient presented with weakness of both lower limbs of two-year duration more on the left side. It was insidious in onset and revealed gradual progression. It progressed to the point when he started having difficulty in getting up from sitting position and developed an ataxic gait. On examination he was found to have spastic paraparesis. R eflexes were increased in both lower. Loss of sensory symptoms was till the inguinal region on left side and up till the knee on right side. On MR Imaging TI and
T2-weighted images revealed dilatation of central canal involving nearly the whole of the thoracic cord, more so from D 5-D 9 [Figure 1]. The signal intensity of the dilated central canal in the distal cord was slightly different from that of the rest of the central canal suggesting the possibility of a lesion within. No enhancement was seen on contrast enhanced images [Figure 2]. There after T2-weighted 3D TSE sequence was performed, which revealed an ill-defined nonenhancing lesion within the central canal in the region

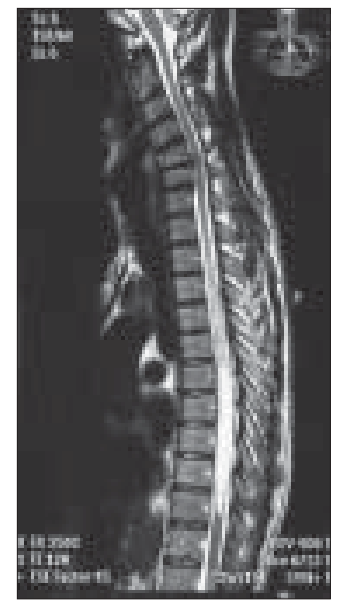

Figure 1: Sagittal T2W image of the Dorso-Lumbar spine reveals dilatation of the central canal predominantly in the D5-D9 region 


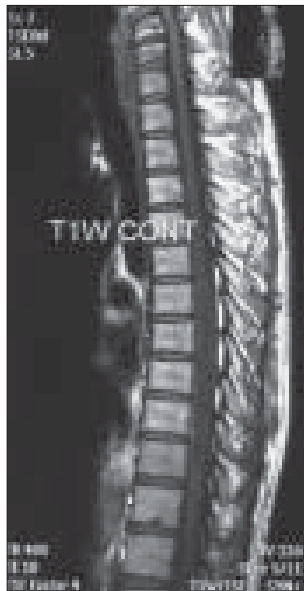

Figure 2: Sagittal T1W contrast enhanced image reveals dilatation of the central canal with no enhancement

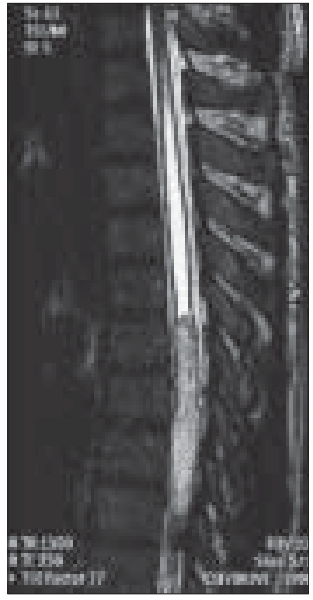

Figure 3: Heavily T2W sagittal image in the same patient reveals the ill-defined non-enhancing tumor within the central canal in the region of D6-D9

of D6-D 9 [Figure 3]. It was central in location with left sided predominance. A diagnosis of Subependymoma was given with ependymoma as a differential diagnosis. Patient was thereafter operated upon. Laminectomy was performed from D6-D 9. After opening the dura and the arachnoidea, myelotomy was performed extending from the lower part of the thickened cord which was highly vascularized. The tumor was soft reddish gray in color and more on the left side. The tumor was excised along the plane of cleavage and near total removal of the tumor was performed. Following surgery the patient made complete recovery. $\mathrm{H}$ istopathology of the excised tumor revealed ependymal cells forming pseudorosettes in a fibrillary background [Figure 4].

\section{Discussion}

Spinal subependymomas are much less frequent than their intracranial counterparts, though they become symptomatically obvious quite early. ${ }^{[5]}$

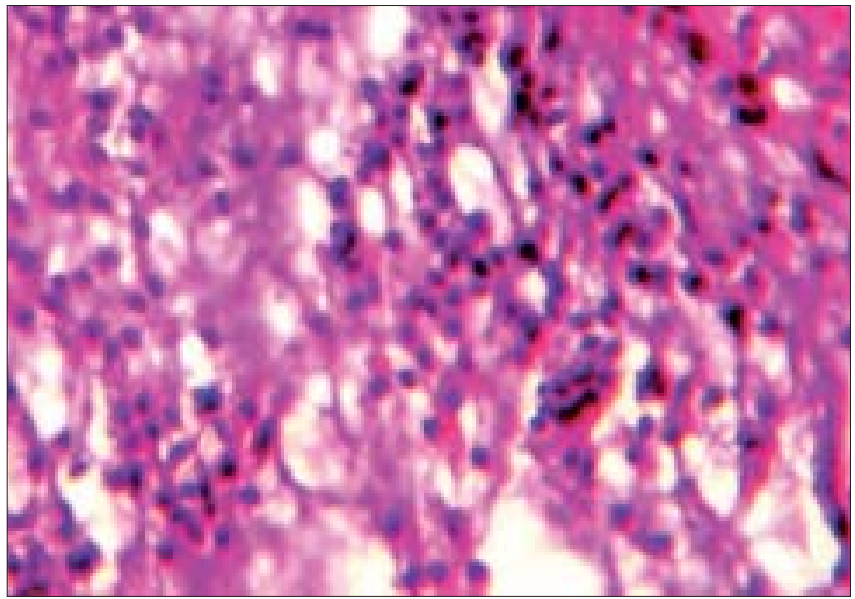

Figure 4: Ependymal cells forming pseudorosettes in a fibrillary background ( $H$ and $E, 100 x$ )

These were first described by Boykin \& al. in 1954, ${ }^{[6]}$ although Schneiker in 1945 first recognized this variant of ependymoma as a distinct entity. ${ }^{[7,8]}$ Thereafter approximately 40 more cases have been described in the literature and that too in the last two decades. ${ }^{[3]}$ Review of literature performed by Sarkar $C$ et al., revealed a mean age of 47.2 years and male predominance. They also found that the majority of tumors were intramedullary and were located in the cervical region. ${ }^{[3]}$

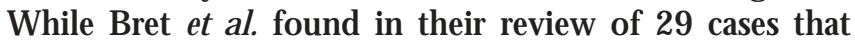
this tumor accounts for approximately $<2 \%$ of all spinal cord tumors and that the majority were located in the cervico-thoracic region. ${ }^{[2]}$

Sarkar et al. on reviewing the literature found no difference on imaging studies between ependymomas and subependymomas. ${ }^{[3,4,8-10]}$ They reviewed the imaging findings of forty cases reported in the literature and found that computed tomography (CT) scan reported in eight cases showed spinal cord enlargement in three and cyst in one. Only two patients showed post contrast enhancement. MRI findings were available for 23 of the 40 reported cases and revealed segmental fusiform dilatation of the cord with low T1-weighted and high T2-weighted signal intensities. Contrast studies were available in 18 of these 23 cases. Ten of 18 cases showed enhancement with contrast, either well circumscribed sharply demarcated areas of homogenous signal enhancement or multiple nodular enhancements. ${ }^{[3,4,6]}$ To the best of our knowledge imaging appearance similar to ours has not been described.

These tumors are biologically benign with very low proliferation index. ${ }^{[11]}$ They are eccentrically located within the spinal cord, enabling complete tumor removal in most cases. ${ }^{[3]}$ Surgical removal is usually curative and no further adjunct treatment like radiotherapy should

Indian Journal of Cancer | January-March 2008 | Volume 45 | Issue 1 
be given after gross total tumor removal. Radiotherapy given in patients with partial removal of tumor has shown no evidence of any efficacy. ${ }^{[12]}$

Prognosis is thus determined largely by surgical factors. No recurrence or CSF seedings have been reported till date. ${ }^{[4]}$

\section{References}

1. Matsumoto K, Nakagaki H. Intramedullary subependymoma occupying the right half of the thoracic spinal cord: A case report. Neurol Med Chir Tokyo 2002;42:349-53.

2. Bret P, Bougeard R, Saint-Pierre G, Guyotat J, Ricci AC, Confavreux C. Intramedullary subependymoma of the cervical spinal cord: Review of the literature a propos of a case. Neruchirurgie 1997;43:158-63.

3. Sarkar C, Mukhopadhyay S, Ralte AM, Sharma MC, Gupta A, Gaikwad S, et al. Intramedullary subependymoma of the spinal cord: A case report and review of literature. Clin Neurol Neurosurg 2003; 106:63-8.

4. Dario A, Fachinetti P, Cerati M, Dorizzi A. Subependymoma of the spinal cord: Case report and review of the literature. J Clin Neurosci 2001;8:48-50.

5. Wiestler OD, Schiffer D. Subependymomas. In: Kleihues P, Cavenee WK, editors. Pathology and genetics: Tumors of the nervous system. Lyon: IARC Press; p. 80-1.

6. Boykin FC, Cowen D, lannucci CA, Wolf A. Subependymal glomerate astrocytomas. J Neuropathol Exp Neurol 1954;13:30-49.

7. Scheinker JM. Subependymoma: Newly recognized tumour of subependymal derivation. J Neurosurg 1945;49:232-40.

8. Kremer P, Zoubaa S, Schramm P. Intramedullary subependymoma of the lower spinal cord. Br J Neurosurg 2004; 18:548-51.

9. Pagni CA, Canavero S, Giordana MT, Mascalchi M, Arnetoli G. Spinal intramedullary subependymomas: Case report and review of the literature. Neurosurgery 1992;30:115-7.

10. Hoeffel C, Boukobza M, Polivka M, Lot G, Guichard JP, Laffitte F, et al. MR manifestations of subependymomas. AJNR Am J Neuroradiol 1995; 16:2121-9.

11. Jallo GI, Zagzag D, Epstein F. Intramedullary subependymoma of the spinal cord. Neurosurgery 1996;38:251-7.

12. Taciomi L, Johnston FG, Thomas DG. Subependymoma of the cervical cord. Clin Neurol Neurosurg 1996;98:24-6.

Source of Support: Nil, Conflict of Interest: None declared. 